\title{
THE SERUM PROTEINS IN PORTAL CIRRHOSIS UNDER MEDICAL MANAGEMENT. ELECTROPHORETIC STUDIES ${ }^{1}$
}

\author{
By KENNETH STERLING,2 WILLIAM E. RICKETTS, JOSEPH B. KIRSNER, \\ AND WALTER L. PALMER \\ (From the Frank Billings Medical Clinic, Department of Medicine, The University of Chicago, \\ Chicago, Ill.)
}

(Received for publication May 9, 1949)

\begin{abstract}
Alterations in the composition of the serum proteins in hepatic disease have been studied by numerous workers using the electrophoretic method (1-11). The present investigation was undertaken to determine the changes in the serum proteins in portal cirrhosis by serial electrophoretic analyses during the course of prolonged medical management.
\end{abstract}

\section{METHODS}

Electrophoretic runs were performed with standard apparatus and technique, the experimental details having been given in an earlier report (11). The tests of hepatic function were performed by the usual methods as previously described (11), alkaline phosphatase being reported in Bodansky units.

\section{CASE MATERIAL}

The ten cases of the present study were all chronic alcoholics considered to have proven portal cirrhosis. The diagnosis was confirmed histologically by VimSilverman needle biopsy of the liver in seven of the ten cases, and in one patient (R. M. S.) also by autopsy. In one case (P. F.) the cirrhotic liver was visualized by peritoneoscopy and subsequently during an umbilical herniorrhaphy, but tissue for biopsy was not obtained. In two clinically typical cases (J. H. and C. R.), needle biopsy was attempted, yielding minute amounts of fibrous tissue considered insufficient for histologic diagnosis.

The ten cases were divided into two groups.

Group I. Five patients with hepatic insufficiency and ascites were studied with serial electrophoretic analyses of the serum proteins and various tests of hepatic function during the course of medical management for periods ranging up to ten months.

The initial electrophoretic analysis designated as "Day 0 " was carried out before or very early in the course of medical management. Although a few patients had re-

1 This investigation has been made with the assistance of a grant from the Committee on Therapeutic Research, Council on Pharmacy and Chemistry, of the American Medical Association.

2 Present address: Department of Medicine, Harvard Medical School, Boston, Mass. ceived some form of therapy elsewhere prior to study, with one exception none had followed an adequate dietary regime for any appreciable period.

Group II. Five patients were studied after sustained clinical recovery under medical management. These individuals had been severely ill with hepatic insufficiency; ascites requiring paracenteses had been present in four, and pronounced jaundice in one. With treatment they had clinically recovered and had remained asymptomatic for more than two years.

\section{THERAPEUTIC REGIME}

The basic therapeutic regime consisted of a diet high in protein, carbohydrate and calories, containing 120 to 150 grams of protein, 350 to 450 grams of carbohydrate, a total of 3000 to 3500 calories, supplemented by 4 to 6 grams of choline chloride per day. The intake of sodium was restricted to $500 \mathrm{mg}$. per day in the patients in Group I as long as clinical evidence of ascites remained. The dietary regime was rigidly enforced during the hospital stay; after discharge patients were strongly urged to adhere to the diet, and were closely followed with numerous clinic visits. Not more than one paracentesis was done on any patient during the study; mercurial diuretics were used infrequently.

Other measures such as infusions of plasma or human albumin were employed as noted below. Salt-poor concentrated human albumin was given as a $25 \%$ solution by slow intravenous infusion.

\section{RESULTS}

Group I. The initial electrophoretic analyses (Day 0) disclosed marked diminutions of the albumin fractions and elevations of the gammaglobulin fractions; the beta-globulins were somewhat less elevated ( $c f$. normal serum, Figure 6 and Table VI).

J. K.-51 year old male. Hematemesis and melena occurred after an alcoholic debauch of two weeks' duration. On admission the patient had very severe jaundice, edema and ascites. Complete clinical recovery with subsidence of jaundice and disappearance of ascites occurred after three months of treatment. The patient remained free 


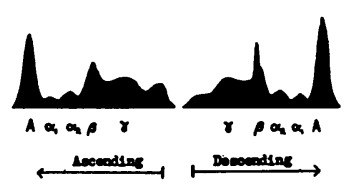

Day 0

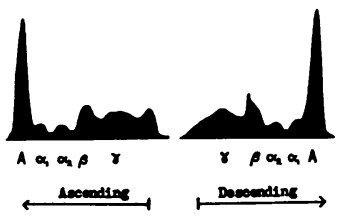

Dar 150

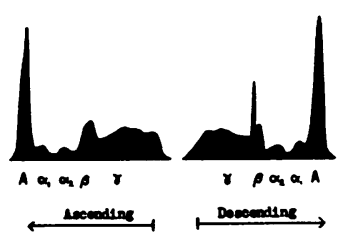

Day 74

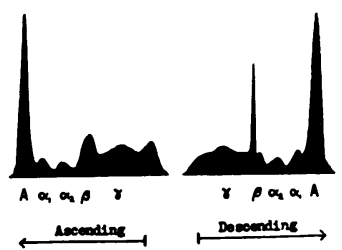

Dag 207

\begin{abstract}
J.K. - 51 year old male. Chronic alcoholic. Hematemesis and melena, extreme jaundice, ascites with paracentesis. Complete clinical recovery with disappearance of ascites on dietary regime.

Fig. 1. The Albumin Peaks Are Indicated by “A," and the Globulins by Their Respective Greek Letter Prefixes. The Unlabelled Peaks Are the Stationary Anomalous Boundaries Due to Gradients of Buffer SALT
\end{abstract}

of symptoms during almost five months of subsequent observation.

Serial electrophoretic analyses (Figure 1 and Table I) revealed pronounced evolution of the serum protein pattern toward normal. The tests of hepatic function also changed in the direction of normal. Despite complete clinical recovery, however, the final electrophoretic pattern on Day 207 was appreciably abnormal.

J. B. -62 year old male. Ascites with peripheral edema and pronounced jaundice had been present for approximately five months. The patient

TABLE I

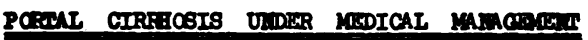

Sore of J.X.

\begin{tabular}{|c|c|c|c|c|c|c|c|c|c|c|c|c|c|c|c|c|c|c|c|c|c|}
\hline & \multicolumn{11}{|c|}{ Bloctrophoret1c Date } & \multicolumn{4}{|c|}{ Howe sodium oulfate } & \multirow{3}{*}{\multicolumn{2}{|c|}{$\frac{\text { b1lirrab }}{d s r}$}} & \multirow[b]{3}{*}{ ooph } & \multirow{3}{*}{ thang } & \multirow[b]{3}{*}{$\begin{array}{l}\text { alk } \\
\text { phos }\end{array}$} & \multirow[b]{3}{*}{$\frac{198}{8}$} \\
\hline & \multicolumn{5}{|c|}{ per cont } & \multicolumn{5}{|c|}{ grems por cont } & \multirow[b]{2}{*}{$A / G$} & \multirow[b]{2}{*}{$A / G$} & \multicolumn{3}{|c|}{ examg por cont } & & & & & & \\
\hline & Alb & $\alpha_{1}$ & $\alpha_{2}$ & $\beta$ & $\gamma$ & Alb & $\alpha_{1}$ & $\alpha_{2}$ & $\beta$ & $\gamma$ & & & ALb & Glob & Tot & & & & & & \\
\hline Day 0 & 33.3 & 4.1 & 7.4 & 26.9 & 28.3 & 1.87 & 0.23 & 0.41 & 1.51 & 1.59 & 0.50 & 0.58 & 2.05 & 3.56 & 5.61 & 15.0 & 18.1 & $3+$ & & 17.8 & \\
\hline Day 74 & 40.5 & 5.5 & 6.6 & 18.5 & 28.9 & 2.77 & 0.38 & 0.45 & 1.26 & 1.97 & 0.68 & 0.86 & 3.16 & 3.67 & 6.83 & 0.9 & 1.9 & $3+$ & 8 & $-\infty$ & 47 \\
\hline Day 150 & 44.9 & 6.0 & 6.9 & 20.4 & 21.8 & 2.87 & 0.38 & 0.44 & 1.31 & 1.40 & 0.82 & 1.01 & 3.21 & 3.19 & 6.40 & 0.2 & 0.9 & $3+$ & 实 & 5.2 & 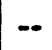 \\
\hline Dey 207 & 45.6 & 6.6 & 5.8 & 19.4 & 22.6 & 2.87 & 0.42 & 0.37 & 1.22 & 1.42 & 0.84 & 1.27 & 3.53 & 2.77 & 6.30 & 0.4 & 1.2 & $1+$ & & $\ldots$ & 44 \\
\hline
\end{tabular}




\section{PORTLL CIERTOSIS UNDER MEDICAL MMUGEMENT}

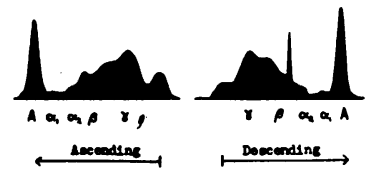

Day 0

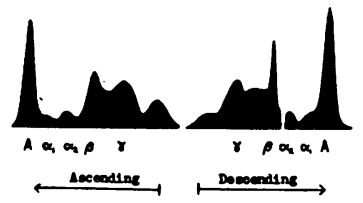

Day 77

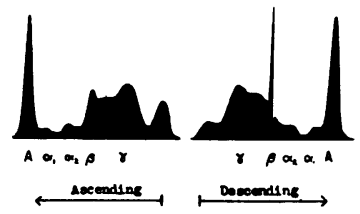

$\underline{D} 317$

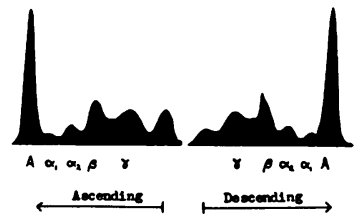

Day 140

J.B. - 62 year old male. Chronic alcoholic. Pronounced jaundice and ascites. Partial clinical improvement with disappearance of ascites on dietary regime to which patient did not adhere satisfactorily.

FIG. 2

improved only partially, and after discharge from the hospital did not adhere to the diet. The ascites disappeared in one month, but the jaundice persisted during the subsequent five months of observation.

The electrophoretic patterns (Figure 2 and Table II) revealed pronounced evolution toward normal (fully as marked as in J. K.). The last pattern on Day 140, however, was appreciably abnormal.
M. S. -56 year old female. Jaundice had been present for six months; the patient was admitted to the hospital three weeks after the onset of ascites and edema of the ankles. On the dietary regime partial clinical recovery ensued during a period of five months, with subsidence of jaundice and ascites; the improvement was maintained during five additional months of observation, although the patient had not fully regained her usual vigor and sense of well-being.

TABLE II

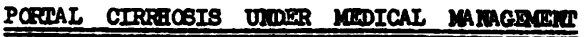

sera of J.B.

\begin{tabular}{|c|c|c|c|c|c|c|c|c|c|c|c|c|c|c|c|c|c|c|c|c|}
\hline & \multicolumn{11}{|c|}{ Electrophoret1c date } & \multicolumn{4}{|c|}{ Eowe sodium oulfate } & \multirow{3}{*}{\multicolumn{2}{|c|}{$\frac{b 11 \text { trab }}{\left.d r\right|^{t}}$}} & \multirow{3}{*}{ eoph } & \multirow[b]{3}{*}{ athy } & \multirow{3}{*}{ |late } \\
\hline & \multicolumn{5}{|c|}{ per cont } & \multicolumn{5}{|c|}{ exemp per cont } & \multirow[b]{2}{*}{$A / G$} & \multirow[b]{2}{*}{$A / G$} & \multicolumn{3}{|c|}{ Exang per cont } & & & & & \\
\hline & Alb & $\alpha_{1}$ & $\alpha_{2}$ & $\boldsymbol{\beta}$ & $\gamma$ & AIb & $\alpha_{1}$ & $\alpha_{2}$ & $\beta$ & $\gamma$ & & & Alb & alob & Tot & & & & & \\
\hline Day 0 & 28.1 & 2.2 & 4.3 & 32.6 & 32.8 & 1.82 & 0.14 & 0.28 & 2.10 & 2.12 & 0.39 & 0.44 & 1.96 & 4.50 & 6.46 & 5.4 & 8.3 & 24 & 10.7 & 5.4 \\
\hline Day 17 & 29.7 & 3.4 & 5.9 & 30.6 & 30.4 & 2.39 & 0.27 & 0.47 & 2.48 & 2.45 & 0.42 & 0.47 & 2.56 & 5.50 & 8.06 & 4.1 & 6.5 & 34 & 12.1 & 8.5 \\
\hline Day 77 & 35.1 & 3.7 & 6.6 & 28.6 & 26.0 & 2.79 & 0.29 & 0.52 & 2.27 & 2.07 & 0.54 & 0.58 & 2.92 & 5.02 & 7.94 & 3.2 & 6.0 & $4+$ & 16.8 & 9.4 \\
\hline Day 140 & 42.8 & 3.5 & 7.9 & 22.4 & 23.4 & 3.26 & 0.27 & 0.59 & 1.70 & 1.78 & 0.75 & 0.59 & 2.82 & 4.78 & 7.60 & 2.8 & 6.0 & $4+$ & 15.2 & 10.2 \\
\hline
\end{tabular}




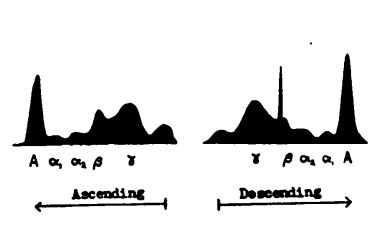

Day 0

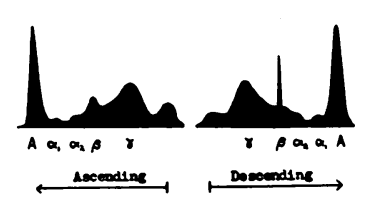

Day 45

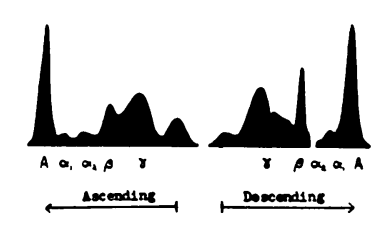

Das 150

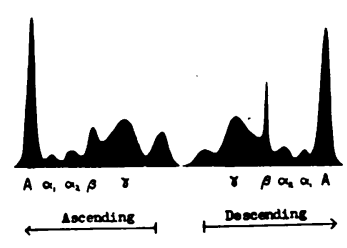

Day 276

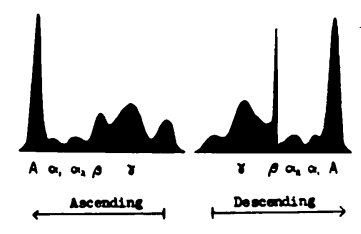

Day 304

M.S. - 56 year old female. Chronic alcoholic. Jaundice and ascites. Partial clinical recovery with disappearance of ascites on dietary regime.

FIG. 3

The serial electrophoretic patterns (Figure 3 and Table III) indicated a very gradual change in the direction of normal, but after the relatively asymptomatic period of five months, the pattern still remained markedly abnormal with a pronounced elevation of the gamma-globulin fraction (Day 304).

R. M. S. -43 year old male. Manifestations of cirrhosis had been present for more than two years with spider angiomata, episodes of jaundice, melena, edema and ascites necessitating paracentesis. Prior to admission, the patient had received elsewhere plasma, choline, and Vitamin $\mathrm{K}$, as well as dietary treatment. The ascites disappeared after medical management including plasma infusions (3000 $\mathrm{cc}$. in nine days). Just

TABLE III

POENAL CIRRHOBTS ULOER MLDICAL MAMACEMETI

Sere of M.S.

\begin{tabular}{|c|c|c|c|c|c|c|c|c|c|c|c|c|c|c|c|c|c|c|c|c|c|}
\hline & \multicolumn{10}{|c|}{ Eloctrophoret10 date } & & \multicolumn{4}{|c|}{ Howe sodium sulfate } & \multirow{3}{*}{\multicolumn{2}{|c|}{$\frac{b 111 r u b}{\left.d r\right|^{\text {tot }}}$}} & \multirow{3}{*}{ oeph } & \multirow[b]{3}{*}{ thym } & \multirow[t]{2}{*}{ • } & \multirow{3}{*}{$\frac{\text { PSP }}{\%}$} \\
\hline & \multicolumn{5}{|c|}{ per cont } & \multicolumn{5}{|c|}{ eremg per cont } & \multirow[b]{2}{*}{$A / G$} & \multirow[b]{2}{*}{$A / G$} & \multicolumn{3}{|c|}{ erems per cent } & & & & & & \\
\hline & $A I b$ & $\alpha_{1}$ & $\alpha_{2}$ & $\beta$ & $\gamma$ & Alb & $\alpha_{1}$ & $\alpha_{\lambda}$ & $\beta$ & $\gamma$ & & & Alb & Glob & Tot & & & & & phos & \\
\hline Day 0 & 31.0 & 5.0 & 8.0 & 27.0 & 39.0 & 2.01 & 0.32 & 0.52 & 1.10 & 2.53 & 0.45 & 0.65 & 2.56 & 3.92 & 6.48 & 0.9 & 2.3 & $4+$ & 7.4 & 7.5 & 99 \\
\hline Day 45 & 34.9 & 3.5 & 4.3 & 13.6 & 43.7 & 2.42 & 0.24 & 0.30 & 0.94 & 3.04 & 0.54 & 0.68 & 2.81 & 4.13 & 6.94 & 1.7 & 2.4 & $3+$ & 10.7 & 9.2 & 210 \\
\hline Day 150 & 35.8 & 3.9 & 7.1 & 18.8 & 34.4 & 2.41 & 0.26 & 0.48 & 1.27 & 2.32 & 0.56 & 0.75 & 2.89 & 3.85 & 6.74 & 0.8 & 1.5 & $4+$ & 6.8 & 12.9 & -- \\
\hline Day 276 & 39.3 & 4.4 & 6.9 & 13.4 & 36.0 & 2.56 & 0.29 & 0.45 & 0.87 & 2.34 & 0.65 & 0.96 & 3.19 & 3.32 & 6.51 & 0.7 & 2.1 & 34 & 7.2 & 12.0 & $\mathscr{2}$ \\
\hline Day 304 & 39.3 & 4.3 & 6.8 & 14.9 & 34.7 & 2.69 & 0.29 & 0.47 & 1.02 & 2.37 & 0.65 & 1.04 & 3.48 & 3.36 & 6.84 & 0.6 & 1.2 & $4 t$ & 8.2 & 12.3 & 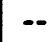 \\
\hline
\end{tabular}




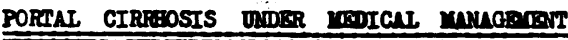

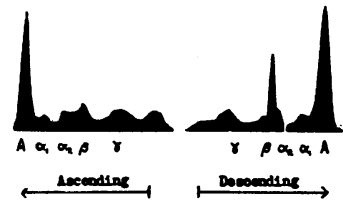

Day 0
0

$3000 \mathrm{cc}$.

in 9 degs

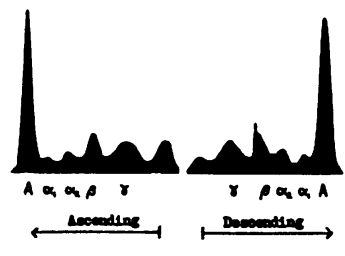

Day 14

R.M.S. - 43 year old male. Chronic alcoholic. Melena, episodes of jaundice, ascites with paracentesis. Ascites disappeared after plasma infusions and dietary regime.

FIG. 4

prior to the intended date of discharge a massive hemorrhage from esophageal varices resulted fatally.

The alterations in serum protein composition were less pronounced in the initial electrophoretic analysis of R. M. S. than in any of the other patients in the group, presumably because of the previous therapy. After the administration of $3000 \mathrm{cc}$. of plasma, the total proteins rose, with increases in both the relative and absolute amounts

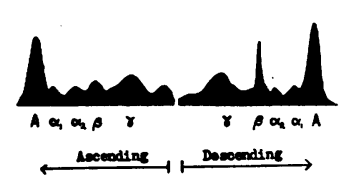

Day 0

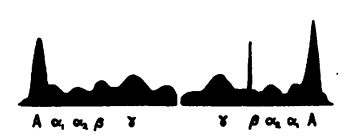

$\stackrel{\text { soceoding }}{\longrightarrow}$ Docoenting

Day 20

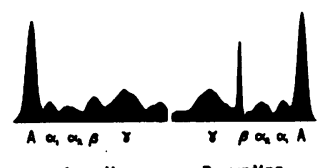

Day 35

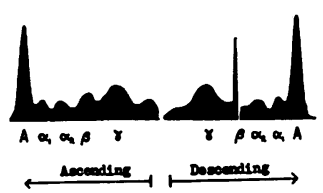

Day 50

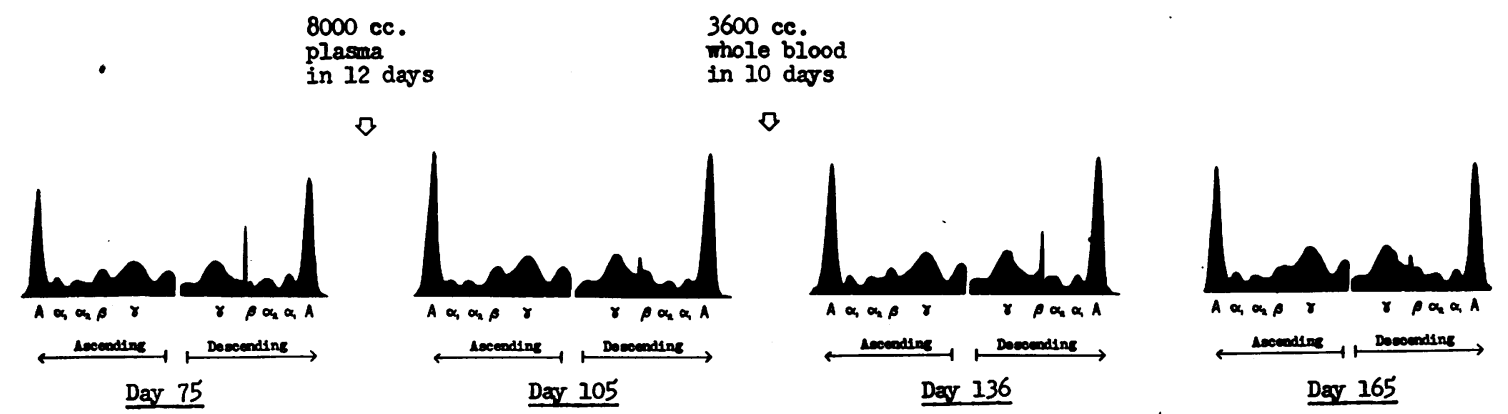

P.F. - 51 year old male. Chronic alcoholic. Marked ascites with repeated paracenteses before admission. Plasma and blood transfusions. Regular diet until Day 108; full dietary regime from Day 108 on.

FIG. 5a 


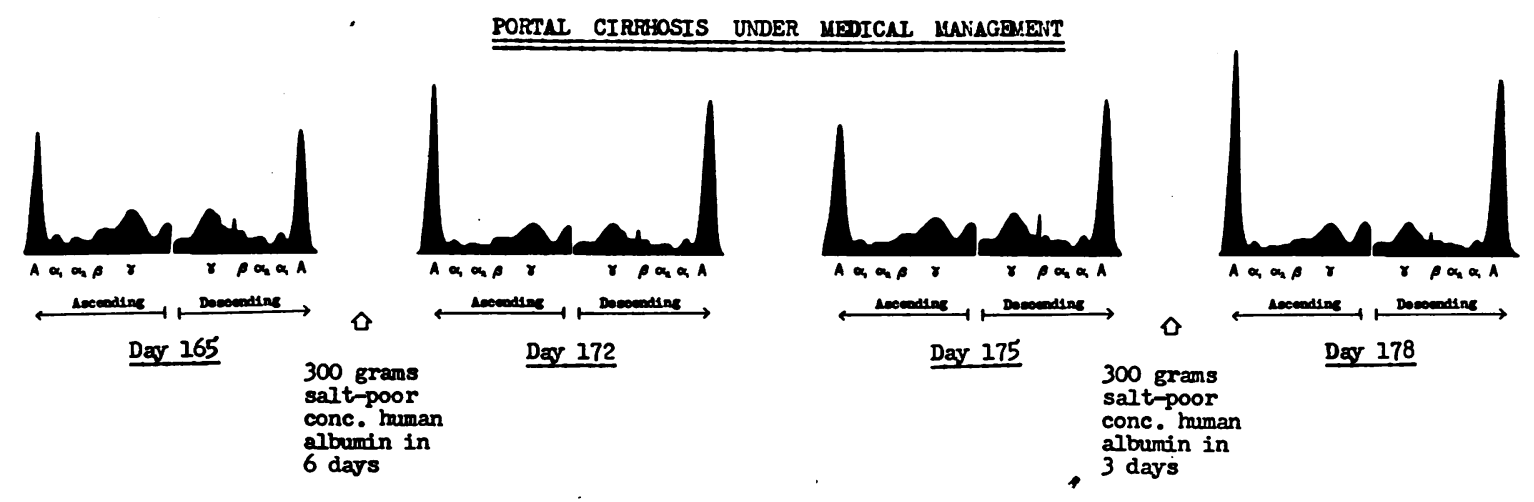

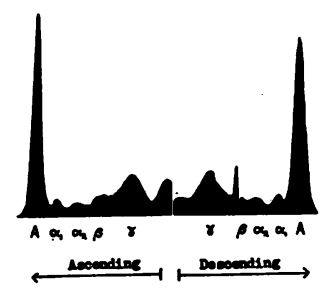

Day 182

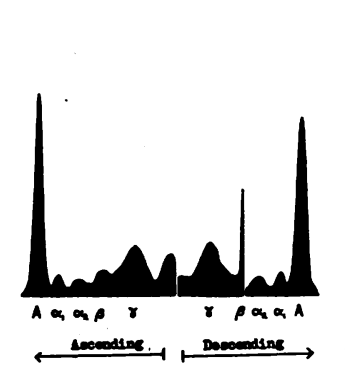

Day 192

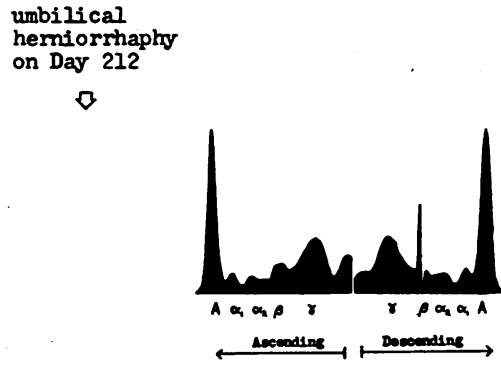

Day 247

P.F. (contimed) - Infusions of salt-poor concentrated muman albumin during dietary regime. Complete clinical recovery with disappeatance of ascites. After discharge patient had partially strangulated umbilical hernia repaired on Day 212 with uneventful recovery." .

FIG. 5b

of albumin and gamma-globulin, and in the absolute amounts of alpha-2- and beta-globulins (Figure 4 and Table IV).

P. F. -51 year old male. Ascites had been present for nine months and was increasing despite repeated paracenteses. On admission, the patient had anasarca and massive ascites, but unlike the other subjects in the group, the serum bilirubin was not elevated.

From Day 0 through Day 86 the patient received a "regular" diet (C 293, P 70, F 62, Cal. 2010) which was, nevertheless, more than he had

TABLE IV

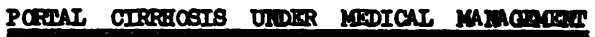

Sora of RX.S.

\begin{tabular}{|c|c|c|c|c|c|c|c|c|c|c|c|c|c|c|c|c|c|c|c|c|c|}
\hline & \multicolumn{11}{|c|}{ Flootropharot 10 deta } & \multicolumn{4}{|c|}{ Howe sodirm oultete } & \multirow{3}{*}{\multicolumn{2}{|c|}{$\frac{b 111 \text { mop }}{d 1 x \mid \text { tot }}$}} & \multirow[b]{3}{*}{ ooph } & \multirow{3}{*}{ then } & \multirow{3}{*}{$\begin{array}{l}\text { alk } \\
\text { phoo }\end{array}$} & \multirow{3}{*}{$\frac{\operatorname{msP}}{\%}$} \\
\hline & \multicolumn{5}{|c|}{ per cont } & \multicolumn{5}{|c|}{ greans per cont } & \multirow[b]{2}{*}{$A / Q$} & \multirow[b]{2}{*}{$A / G$} & \multicolumn{3}{|c|}{ mane per cont } & & & & & & \\
\hline & Alb & $\alpha_{1}$ & $\alpha_{2}$ & $\beta$ & $\gamma$ & Alb & $\alpha_{1}$ & $\alpha_{2}$ & $\beta$ & $\gamma$ & & & Alb & Clob & Tot & & & & & & \\
\hline Dar 0 & 46.8 & 6.7 & 9.1 & 27.4 & 20.0 & 2.48 & 0.36 & 0.48 & 0.93 & 1.06 & 0.88 & 1.35 & 3.05 & 2.26 & 5.31 & 2.1 & 2.8 & 24 & 5.2 & 9.0 & -- \\
\hline Das 14 & 48.0 & 5.0 & 9.0 & 15.9 & 22.1 & 3.32 & 0.35 & 0.62 & 1.10 & 1.53 & 0.92 & 1.37 & 4.00 & 2.92 & 6.99 & 2.1 & 2.3 & $2+$ & 13.2 & 8.2 & 70 \\
\hline
\end{tabular}

$p=3000$ cc. of plasma in 9 days 
TABLE V

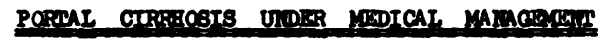

Sera of P.I.

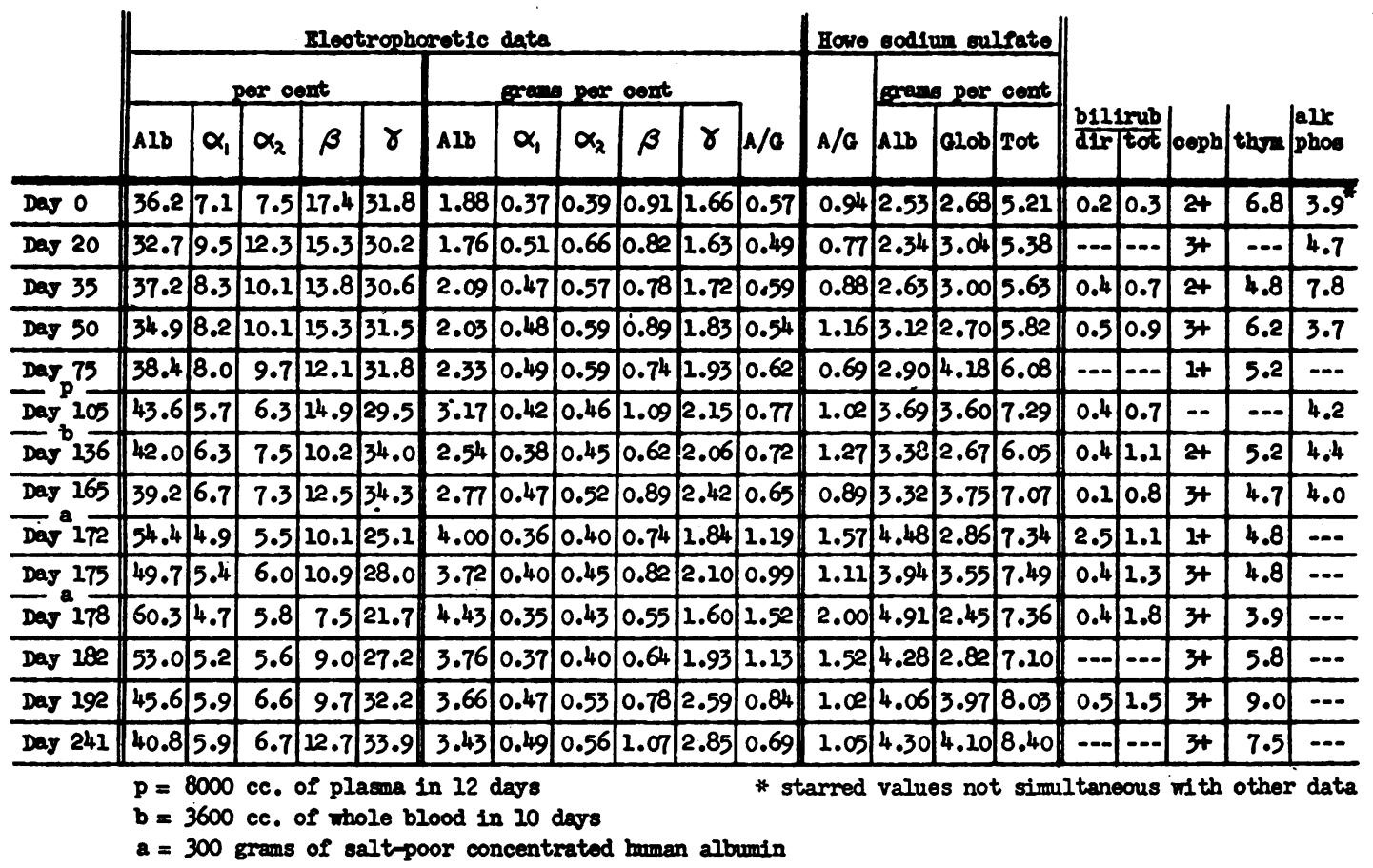

been eating before hospitalization. Partial clinical improvement occurred, with slight diminution of ascites. There was almost 1 gram per cent rise in the total proteins, but relatively little change toward normal in the proportions of the fractions as determined by five electrophoretic analyses (Figures $5 \mathrm{a}$ and $5 \mathrm{~b}$, and Table V). Experiments on electrolyte and water metabolism (to be reported separately) were performed during this period with no significant effect on the electrophoretic pattern.

In the 12-day period of Day 87 through Day 98 while on the "regular" diet, the patient received $8000 \mathrm{cc}$. of plasma. The electrophoretic pattern of Day 105 revealed for the first time a considerable change toward normal.

From Day 108 on the patient was on the full dietary regime (C 437, P 155, F 123, Cal. 3475 supplemented by 5 grams choline chloride). In the ten-day period of Day 126 through Day 135 he received $3600 \mathrm{cc}$. of whole blood. There was no further change of the electrophoretic pattern toward normal (Day 136 and Day 165), but on the contrary, some retrogression.
The intravenous administration of 300 grams of salt-poor concentrated human albumin in six days (Day 166 through Day 171) was followed by a striking elevation of the serum albumin in the electrophoretic pattern of Day 172, while both the relative and absolute values of all globulin fractions were diminished, presumably due to dilution. Three days later (Day 175), the electrophoretic pattern revealed some decline of the serum albumin and rise of the gamma-globulin and other globulin fractions.

After a second course of 300 grams of salt-poor concentrated human albumin, administered in three days (Day 175 through Day 177), a striking elevation of the serum albumin and a diminution of all the globulin fractions again occurred. Once more this was followed by some decline of the serum albumin and a rise of the gamma-globulin and other globulin fractions, this trend being clearly evident in the patterns of Days 182, 192, and 241 , respectively five, 15 , and 64 days after the last infusion of albumin. The ascites disappeared and the patient was discharged on Day 192 completely free of clinical symptoms, and he resumed 
his former occupation. A partially strangulated umbilical hernia was repaired on Day 212 with uneventful recovery. In spite of this episode the final electrophoretic analysis of Day 241 indicated a higher absolute value for serum albumin than at any time prior to institution of the human albumin therapy, and a higher total protein than at any time. Six months after the last albumin infusion the patient remained well, having gained weight with no recurrence of edema or ascites.

Group II. The five cases of portal cirrhosis with long-term clinical recovery under medical management are summarized briefly in Figure 6. The patients had been severely ill with hepatic insufficiency before treatment; four had ascites requiring paracenteses and one had pronounced jaundice; all had hypoalbuminemia, the mean of the albumin values of the five patients being 2.58 grams per cent by Howe sodium sulfate fractionation. As illustrated in Figure 6 and Table VI, the electrophoretic patterns after sustained re- covery appear very nearly normal with but minimal deviations from the normal range.

\section{DISCUSSION}

The five patients in Group I initially had marked diminutions of the albumin fractions and elevations of the gamma-globulin fractions, with somewhat less elevated beta-globulins. During the course of medical management the serum proteins underwent progressive evolution in the direction of normal, coinciding with clinical improvement. The progress of the three patients in the group treated with diet alone indicates that this is not a perfectly strict relationship. J. B., who improved only partially (the ascites disappearing, but the jaundice persisting), had fully as pronounced a change of the electrophoretic pattern toward normal as did J. K. with complete clinical recovery. Moreover, M. S., whose clinical improvement was more marked than J. B.'s, had less evolution toward a normal serum protein composition, the

POPTAL CIRPHOSIS WITH LONG-TEFU CLINICAL RECOVERY UNDER WEDICAL MANAGEAENT

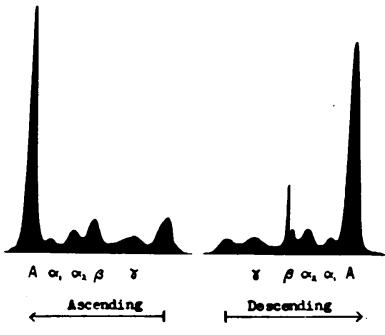

NORALAL SERMM

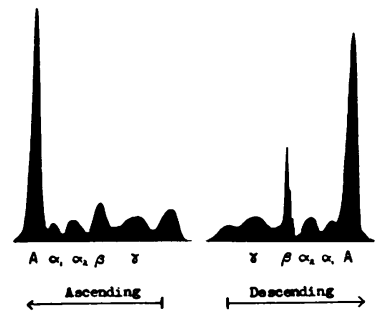

G.0. - 51 year old female. Chronic alcoholic. Jaundice, ascites with repeated paracenteses. Severely ill, in coma for 4 days. After treatment asymptomatic for $2 \frac{1}{2}$ years.

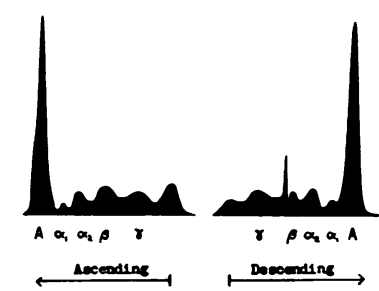

J.H. - 56 year old male. Chronic alcoholic.

Jandice, ascites with paracenteses. After treatnent asymptomatic for 2 years.

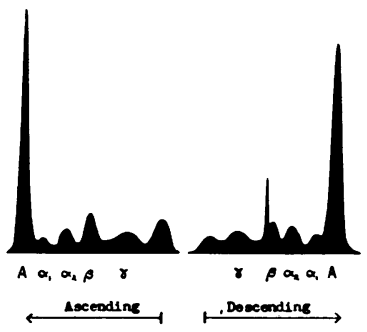

C.R. - 46 year old male. Chronic alcoholic. Jaundice, ascites with paracenteses. After treatment asymptomatic for 5 years.

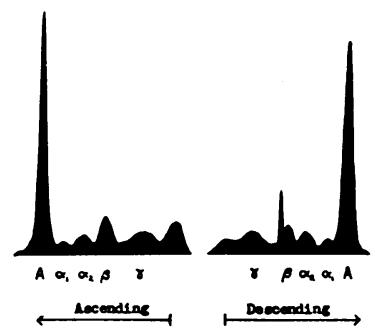

R.S. - 45 year old male. Chronic alcoholic.

Ascites with paracentesis. After treatment asymptomatic for $2 \frac{1}{2}$ years.

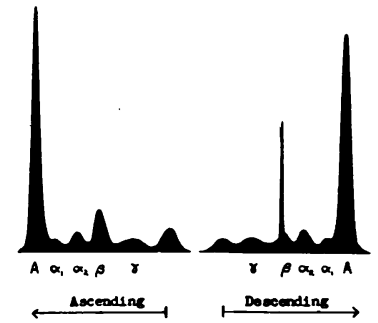

A.E. - 53 year old male. Chronic alcoholic.

-Jaundice, no ascites. After treatnent asymptomatic for $2 \frac{1}{2}$ years. 
TABLE VI

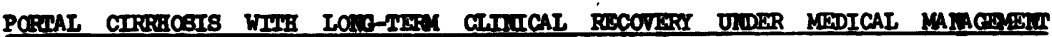

\begin{tabular}{|c|c|c|c|c|c|c|c|c|c|c|c|c|c|c|c|c|c|c|c|c|c|}
\hline & \multicolumn{11}{|c|}{ Eloctrophoret10 date } & \multicolumn{4}{|c|}{ Hove sodivm sulfate } & \multirow{3}{*}{\multicolumn{2}{|c|}{$\frac{b+11 \text { rop }}{d x \mid \text { tot }}$}} & \multirow{3}{*}{ coph } & \multirow{3}{*}{ them } & \multirow{3}{*}{$\mid \begin{array}{l}\text { alk } \\
\text { phos }\end{array}$} & \multirow{3}{*}{$\frac{B S P}{\%}$} \\
\hline & \multicolumn{5}{|c|}{ por cont } & \multicolumn{5}{|c|}{ grams por oont } & \multirow[b]{2}{*}{$A / O$} & \multirow[b]{2}{*}{$A / G$} & \multicolumn{3}{|c|}{ perns port } & & & & & & \\
\hline & ALb & $\mid \alpha_{1}$ & $\alpha_{2}$ & $\beta$ & $\gamma$ & Alb & $\alpha_{1}$ & $\alpha_{2}$ & $\boldsymbol{\beta}$ & $\gamma$ & & & Alb & Glob & Tot & & & & & & \\
\hline J.H. & 56.4 & 3.5 & 9.6 & 15.8 & 24.7 & 3.87 & 0.24 & 0.66 & 1.08 & 1.01 & 1.29 & 1.45 & 4.06 & 2.80 & 6.86 & 0.5 & 0.7 & 24 & 5.3 & 4.7 & 6 \\
\hline R.s. & 58.0 & 4.3 & 8.4 & 14.5 & 14.8 & 3.90 & 0.29 & 0.56 & 0.98 & 1.00 & 2.38 & 1.85 & 4.37 & 2.36 & 6.73 & 0.3 & 0.6 & $3+$ & 9.8 & 2.8 & 13 \\
\hline G.0. & 55.9 & 5.4 & 8.4 & 14.9 & 15.4 & 4.05 & 0.39 & 0.61 & 1.08 & 1.12 & 1.27 & 1.76 & 4.68 & 2.62 & 7.24 & 0.2 & 0.6 & $1+$ & 6.3 & 5.9 & 34 \\
\hline C.R. & 55.2 & 5.4 & 10.2 & 16.2 & 23.0 & 3.84 & 0.38 & 0.71 & 1.32 & 0.90 & 2.23 & $1.7^{4}$ & 4.41 & 2.54 & 6.95 & 0.2 & 0.7 & nog. & 7.9 & 4...2. & -- \\
\hline A.E. & 62.6 & 4,0 & 8.2 & 16.8 & 8.4 & 4.13 & 0.26 & 0.54 & 2.21 & 0.55 & 1.68 & 2.68 & 4.77 & 1.82 & 6.59 & 0.1 & 0.6 & nog. & 1.3 & 2.6 & 3 \\
\hline AVIRPACS: & 57.6 & 4.5 & 9.0 & 15.6 & 13.3 & 3.96 & 0.31 & 0.62 & 1.07 & 0.91 & 1.37 & 1.8 & 4.44 & 2.43 & 6.87 & & & & & & \\
\hline $\begin{array}{l}\text { Standard } \\
\text { Derlation }\end{array}$ & 0.8 & 0.8 & 0.8 & 1.1 & 2.6 & 1.10 & 0.06 & 0.06 & 0.05 & 0.19 & 0.16 & 0.35 & 0.24 & 0.34 & 0.22 & & & & & & \\
\hline
\end{tabular}

Do:ar gRA

(10 roluntoor oubjects with nocwal 117or sunotion tosts)

\begin{tabular}{l|c|c|c|c|c|c|c|c|c|c|c|c|c|c|c|}
\hline Avipace & 60.3 & 4.0 & 9.7 & 12.8 & 13.2 & 4.23 & 0.28 & 0.68 & 0.89 & 0.93 & 1.52 & 2.31 & 4.89 & 2.12 & 7.021 \\
\hline $\begin{array}{l}\text { Standard } \\
\text { Doviation }\end{array}$ & 2.8 & 0.8 & 1.5 & 1.2 & 1.7 & 0.29 & 0.06 & 0.10 & 0.08 & 0.23 & 0.18 & 0.34 & 0.30 & 0.24 & 0.30 \\
\hline
\end{tabular}

gamma-globulin fraction remaining markedly elevated.

The two cases in Group I considered to have achieved complete clinical recovery, J. K. and P. F., continued to have appreciable abnormalities in the serum protein composition. That the serum protein composition may eventually become normal or nearly so in cases with long-term clinical recovery under medical management is indicated by the five patients in Group II (Figure 6). At the time of admission with hepatic insufficiency these patients all had marked alterations of the serum proteins by the Howe fractionation, which is less sensitive than the electrophoretic technique.

The evaluation of changes in the serum proteins in edematous patients is hazardous unless account is taken of the possibility of shifts in body fluids. Thus an increase in protein concentration may reflect either an increase in the circulating protein or a decrease in the volume of the plasma.

During the observation of P. F., 16 estimations of the plasma volume were made with Evans blue, to be reported separately in connection with studies of electrolyte metabolism. The findings did not indicate that changes of plasma volume would account for the progressive rise of total proteins on dietary therapy or infusions.

In J. K., J. B., and M. S., the three cases treated by diet without infusions, the electrophoretic data alone exclude the possibility that the rise in albumin and total proteins could be solely due to hemoconcentration. These three cases exhibited rise of albumin and decline of gammaglobulin, a circumstance not explicable in terms of any possible fluid shift, and indicating changes in protein metabolism.

In the infusion experiments it appears probable that transitory changes in plasma volume did play a role. The infusion of plasma was followed by increases in the albumin and the beta- and gamma-globulin fractions as well as the total proteins. The immediate effects of intravenous administration of salt-poor concentrated human albumin on the serum protein composition were 
identical with those observed by Thorn, Armstrong, and Davenport (6), i.e., marked elevation of the albumin and depression of the globulin fractions, presumably due to dilution. The changes beginning shortly thereafter consist of some decline of the albumin and rise of the gamma-globulin and other globulin fractions. These ensuing alterations have apparently not been described by previous investigators of human albumin infusion therapy. The phenomenon was observed in the two administrations of human albumin to P. F. and also in a patient with cirrhosis of uncertain etiology not included in the present study. The significance of these observations remains to be determined. It is possible that as the administered albumin left the circulation the plasma volume decreased with resultant concentration of the globulin components.

Comparison of the alterations of the serum proteins with the various tests of hepatic function performed simultaneously fails to reveal any clearly evident direct correlation.

\section{SUM M ARY}

1. The effects of medical management on the serum proteins in ten proven cases of portal cirrhosis have been investigated by the electrophoretic method.

2. Serial electrophoretic analyses of the sera of patients with ascites revealed progressive change in the direction of normal, coinciding with clinical improvement during the administration of a high protein, high carbohydrate, high caloric diet for periods ranging up to ten months.

3. Infusions of plasma or salt-poor concentrated human albumin were followed by pronounced and immediate elevations of the serum albumin values.

4. Shortly after the administration of human albumin, some decline of the elevated albumin value was observed, with rise of the gamma-globulin and other globulin fractions.

5. In five patients who had clinically recovered from severe portal cirrhosis and had been asymp- tomatic for more than two years the electrophoretic patterns were very close to normal.

6. The alterations in the serum protein pattern in portal cirrhosis are not irreversible; with prolonged medical management and clinical recovery, the proteins may revert practically to normal.

The authors wish to express their gratitude to Doctor E. S. Guzman Barron for making available the electrophoretic apparatus used in this study.

\section{BIBLIOGRAPHY}

1. Gray, S. J., and Barron, E. S. G., The electrophoretic analyses of the serum proteins in diseases of the liver. J. Clin. Invest., 1943, 22, 191.

2. Luetscher, J. A., Jr., Electrophoretic analysis of plasma and urinary proteins. J. Clin. Invest., 1940, 19, 313.

3. Luetscher, J. A., Jr., Electrophoretic analysis of the proteins of plasma and serous effusions. J. Clin. Invest., 1941, 20, 99.

4. Kabat, E. A., Hanger, F. M., Moore, D. H., and Landow, $\mathrm{H}$., The relation of cephalin flocculation and colloidal gold reactions to the serum proteins. J. Clin. Invest., 1943, 22, 563.

5. Moore, D. B., Pierson, P. S., Hanger, F. M., and Moore, D. H., Mechanism of the positive cephalincholesterol flocculation reaction in hepatitis. J. Clin. Invest., 1945, 24, 292.

6. Thorn, G. W., Armstrong, S. H., Jr., and Davenport, V. D., Chemical, clinical, and immunological studies on the products of human plasma fractionation. XXXI. The use of salt-poor concentrated human serum albumin solution in the treatment of hepatic cirrhosis. J. Clin. Invest., 1946, 25, 304.

7. Verschure, J. C. M., Elektrophorese en Serumvlokkingsreacties. Scheltema and Holkema's Boekhandel, Amsterdam, 1946.

8. Malmros, H., and Blix, G., The plasma proteins in cases with high erythrocyte sedimentation rate. Acta. med. Scandinav., 1946, Supp. 170, 280.

9. Martin, N. H., The components of the serum proteins in infective hepatitis and in homologous serum jaundice (an electrophoretic study). Brit. J. Exper. Path., 1946, 27, 363.

10. Cohen, P. P., and Thompson, F. L., Mechanism of the thymol turbidity test. J. Lab. \& Clin. Med., 1947, 32, 475.

11. Ricketts, W. E., Sterling, K., Kirsner, J. B., and Palmer, W. L., Electrophoretic studies of the serum proteins in portal cirrhosis. Gastroenterology, in press. 